\title{
Solidified Media Suitable for the Cultivation of Clostridium novyi Type B
}

\author{
By W. B. MOORE \\ The Wellcome Research Laboratories (Biological Division), \\ Langley Court, Beckenham, Kent
}

(Accepted for publication I I May 1968)

\begin{abstract}
SUMMARY
A solidified medium (NP medium) was devised which supported luxuriant growth of Clostridium novyi type B. It consists of peptone, extracts of yeast and liver, blood, glucose and certain other compounds essential as nutrients and/or for poising oxidation-reduction potential. The peptone could be replaced by a commercial preparation of acid-hydrolysed casein or a mixture of 18 amino acids, but the presence of cysteine and either ascorbic acid, thioglycollate (mercapto-acetate) or dithiothreitol (DTT) was essential for consistent rapid and luxuriant surface growth. Blood was not essential in media supplemented with cysteine and DTT, although in its presence the number of colonies which developed was maximal and the formation of zones of haemolysis facilitated the location of smaller colonies. When supplemented with cysteine +DTT several other solidified media, none of which contained yeast-or liver-extract, supported good growth. By incorporating antitoxin into certain clear blood-free plating media containing cysteine + DTT it was possible to show that only some bacilli of a culture produced colonies which developed opaque haloes of toxin antitoxin flocculum. A liquid version of the NP medium was also devised.
\end{abstract}

\section{INTRODUCTION}

Some strains of Clostridium novyi will not grow readily on the surface of solid media such as blood agar (Cruickshank, 1965). In our laboratories the serological types $\mathrm{A}, \mathrm{C}$ and $\mathrm{D}$ have been amenable to this mode of culture, but it has been impossible to obtain regular luxuriant surface growth of type B strains on this and many other solidified media, even when supplemented with horse blood, enzyme digest of horse muscle, yeast extract and auto-digest of pancreas. While this has not precluded detection of contaminant organisms it has proved impossible, so far, to recognize and separate variants of $C$. novyi type B of different colonial morphology. For these reasons, and because studies of the biochemical aspects of toxin formation and the nutritional requirements of this important anaerobe (Batty, Buntain \& Walker, 1964; Cruickshank, I965) were contemplated, it was desirable to have available a plating medium which could be made simply and reproducibly and which could be relied upon to support luxuriant growth of $C$. novyi type B.

Organism. Clostridium novyi type B strain CN 755 was selected from the Culture Collection of the Wellcome Research Laboratories. Stock cultures grown in Robertson's meat broth (RMB) for $18-36 \mathrm{hr}$ at $37^{\circ}$ were kept subsequently at room temperature and subcultured at monthly intervals 
Inocula. When an inoculum was required a subculture from stock was made in fresh RMB and incubated overnight at $37^{\circ}$. Immediately before use the growth was resuspended by gently swirling the culture to form a relatively even suspension of bacteria; this was then left to stand for a few minutes to allow meat particles to settle. Two drops (about $0.06 \mathrm{ml}$.) of bacterial suspension were transferred to $6 \mathrm{ml}$. liquid media, and six drops (about $0.18 \mathrm{ml}$.) to $20 \mathrm{ml}$. portions. With solidified media a single loopful ( $3 \mathrm{~mm}$. diameter) of suspension per plate was streaked when comparisons of colonial morphology were to be made. For more critical assessment of the essential nature of components of media or for comparison of different media, single drops (about $0.03 \mathrm{ml}$./plate) of suspension were delivered from a pipette and spread by a sterile stainless-steel loop (Moore, I966).

Growth in liquid media. Volumes $(6 \mathrm{ml}$.) of liquid medium were contained in screw capped $13 \times 100 \mathrm{~mm}$. Pyrex Culture Tubes (Jobling and Co. Ltd., Sunderland, England); $20 \mathrm{ml}$. volumes were contained in I oz. screw capped bottles (United Glass (England) Ltd., Staines, Middlesex). After aseptic addition of sterile supplements and inoculum, the caps were screwed down tightly and the vessels incubated at $37^{\circ}$.

Growth on solidified media. Sterile plastic Petri dishes (Sterilin, Richmond, Surrey, England) were used. Anaerobic conditions were maintained by the use of modified McIntosh \& Fildes jars (Baird and Tatlock, Ltd., Chadwell Heath, Essex, England; see Batty \& Walker, I965). Before use, the insides of the jars were washed with clean warm water and dried, and an extra satchet of palladium catalyst was placed on the bottom of the jar (Irene Batty, personal communication); these satchets were renewed after the jars had been used three or four times. After streaking, plates were placed quickly inside the anaerobic jar. This was evacuated to $0 . \mathrm{I} \mathrm{mm}$. $\mathrm{Hg}$, filled with a mixture of hydrogen and carbon dioxide $\left(95 \%, \mathrm{v} / \mathrm{v}, \mathrm{H}_{2}+5 \%, \mathrm{v} / \mathrm{v}, \mathrm{CO}_{2}\right)$, re-evacuated and re-filled with more gas mixture. Incubation was at $37^{\circ}$.

Measurement of growth in liquid media. The opacities of cultures were read with an EEL colorimeter and are expressed in terms of extinction at appropriate wavelengths. Since different media varied in colour and absorbancy it was necessary to vary the filters used. For any one experiment the filter chosen was one which allowed adjustment of the instrument to $100 \%$ transmission when blanks of uninoculated media were inserted. The filters used were nos. 47,49 and 70 , which transmit maximally at $465 \mathrm{~m} \mu$ and $680 \mathrm{~m} \mu$, respectively. By use of an adaptor the Pyrex culture tubes could be inserted directly into the instrument thus enabling repeated measurements of opacity in situ. With I oz. bottles it was most convenient to tip a portion of the culture into a 6 in. $\times \frac{5}{8}$ in. bacteriological test tube used as optical cell.

Measurement of growth on solidified media. The amount of growth on plated cultures was assessed by gross appearance and is described as luxuriant, good, fair, poor or nil corresponding to the presence of more than $500 ; 200$ to $500 ; 50$ to 200 ; 10 to 50 and o colonies/plate.

Medium constituents. Yeast extract, Trypticase Soy Agar, Trypticase Soy Broth, Bacto Tryptose, Bacto Tryptone, Neopeptone, Vitamin-free Casamino-acids and agar (Noble) were all Difco products. The liver extract was a dried preparation (Pabryn Laboratories, Greenford, Middlesex). Inorganic salts, glucose, ascorbic acid, cysteine hydrochloride and glutamine were of A.R. quality (British Drug Houses Ltd.). Dithiothreitol (DTT) A grade, was obtained from Calbiochem Ltd. All solutions were made in glass-distilled water. 
Sterilization. The basal portion of all media used, containing a nitrogen source, yeast extract (YE), liver extract (LE), glucose and agar, was autoclaved at $12 \mathrm{I}^{\circ}$ for I5 min. Solutions of ascorbic acid, cysteine, glutamine and DTT (of unknown thermal stability) were filtered through Millipore GS membranes just before use.

Photomicrography. Colonies and Nigrosin smear-preparations of bacteria were photographed under a Vickers projection microscope.

\section{RESULTS}

First attempts to obtain a plating medium used a papain digest of horse muscle ( $\mathrm{pH} \mathrm{7.60)} \mathrm{supplemented} \mathrm{with} \mathrm{growth} \mathrm{factors} \mathrm{of} \mathrm{the} \mathrm{vitamin} \mathrm{B} \mathrm{complex,} \mathrm{glucose} \mathrm{and}$ glycyl-L-asparagine (Takarabe, 1960) and was solidified with agar (I \% or $3 \%$, w/v). Although the liquid cultures, from which inocula were taken, always appeared by phase microscopy to contain numerous viable (non-granular) bacilli, their cultivation on the above solid medium met with only sporadic success.

It was realized that unknown essential factors, possibly of a peptide nature, might be missing, but it was suspected that labile thiol compounds were more probably involved. The loss of these to varying and usually decisive extents each time plates were poured and dried could well account for the variable growth responses observed. Attempts to simulate a solidified version of Robertson's meat broth by inclusion of subsurface meat particles and cysteine in the above medium were attended with success only occasionally. It was difficult to overlay sterile meat particles, placed in a Petri dish, with molten medium, and the final surface was invariably interrupted by protrusion of larger particles. Such a medium was therefore not easy to make or reproduce. Homogenization of the meat particles resulted in complete failure of the medium. Subsequent work showed that maintenance of the agar surfaces in a moist condition was not a factor decisive for growth.

Following the report of Khairat (I966) who described a medium for the cultivation of many fastidious obligate anaerobes, a fresh approach was made to the cultivation of Clostridium novyi type B on solidified medium. Khairat stressed the synergistic effect of yeast and liver extracts and attributed much of the success of his medium to this. Commercial preparations of yeast and liver extracts were mixed with agar and glucose and different commercial sources of nitrogen (Bacto Tryptone, Trypticase Soy Agar, Trypticase Soy Broth, Neopeptone) were added singly to form various basal media. Sterile molten portions of each (at $\mathrm{pH} 7 \cdot 60$ ) were then supplemented aseptically with horse blood and a sterile solution containing ascorbic acid, cysteine, glutamine and DTT. Plates were quickly poured, dried (I5 min., $37^{\circ}$ ), streaked and then incubated anaerobically. Dithiothreitol was used following the report by Cleland (1964) of its low oxidation-reduction potential $(-0.33 \mathrm{~V}$ at $\mathrm{pH} 7.0)$ and its use for the specific protection of labile thiol compounds. From a qualitative assessment of growth the medium containing Neopeptone was chosen as the best and most economical, and is referred to subsequently as NP medium. Growth of C. novyi type B CN 755 on this is shown in Pl. I, fig. I.

\section{Composition of liquid media}

Omission of horse blood and agar produced liquid NP medium which gave heavy growth of Clostridium novyi within $\mathrm{I} 8 \mathrm{hr}$ at $37^{\circ}$. Neopeptone could be replaced by acid hydrolysate of casein (CA medium) or a mixture of eighteen amino acids (Aa medium) 
each present at concentrations between 50 and $100 \mu \mathrm{g} . / \mathrm{ml}$. Growth in this latter medium, however, was very poor as compared with growth in NP medium or CA medium. In NP medium a supplement of cysteine only was essential, whereas in CA medium a mixture of cysteine with either ascorbic acid or DTT was essential (Table I). CA medium did not support such heavy total growth as NP medium so that the essential nature of cysteine in the CA medium was less clearly shown.

Table I. Growth of Clostridium novyi type B CN755 in liquid NP and CA media supplemented with ascorbic acid, cysteine and dithiothreitol, separately and in combination

Supplements: (A) ascorbic acid $250 \mu \mathrm{g} . / \mathrm{ml}$., (C) cysteine $100 \mu \mathrm{g} . / \mathrm{ml}$., (D) dithiothreitol $100 \mu \mathrm{g} . / \mathrm{ml}$. Unwashed inoculum $=$ culture of $C$. novyi grown for $24 \mathrm{hr}$ in Robertson meat broth and then subcultured into liquid NP medium supplemented with cysteine $(100 \mu \mathrm{g} . / \mathrm{ml}$.), glutamine ( $50 \mu \mathrm{g} . / \mathrm{ml}$.), dithiothreitol (100 $\mu \mathrm{g} . / \mathrm{ml}$.); $\mathrm{pH} 7 \cdot 80 ; 6$ drops $(0 \cdot 18 \mathrm{ml}$.) transferred to each $20 \mathrm{ml}$. portion of test medium. Washed inoculum $=5 \mathrm{ml}$. of the same culture centrifuged aseptically, supernatant phase discarded and bacteria resuspended in $5 \mathrm{ml}$. of sterile quarter-strength Ringer solution; 2 drops transferred to each $20 \mathrm{ml}$. portion of test medium. Glutamine $(50 \mu \mathrm{g} . / \mathrm{ml}$.) was present in all test systems.

\begin{tabular}{|c|c|c|c|c|}
\hline \multirow[b]{2}{*}{ Supplements } & \multicolumn{2}{|c|}{ Basal CA medium } & \multicolumn{2}{|c|}{ Basal NP medium } \\
\hline & $\begin{array}{l}\text { Washed } \\
\text { inoculum }\end{array}$ & $\begin{array}{l}\text { Unwashed } \\
\text { inoculum }\end{array}$ & $\begin{array}{l}\text { Washed } \\
\text { inoculum }\end{array}$ & $\begin{array}{l}\text { Unwashed } \\
\text { inoculum }\end{array}$ \\
\hline$A+C+D$ & $0.69^{*}$ & 0.70 & 0.99 & $1 \cdot 0 I$ \\
\hline $\mathrm{C}+\mathrm{D}$ & 0.60 & 0.56 & I.OI & $I \cdot 02$ \\
\hline$A+D$ & 0.31 & 0.30 & 0.28 & 0.36 \\
\hline$A+C$ & 0.60 & 0.65 & $I \cdot I 6$ & $\mathbf{I} \cdot \mathbf{I} 2$ \\
\hline D & 0.0 & 0.0 & 0.26 & 0.25 \\
\hline $\mathbf{C}$ & 0.0 & 0.0 & $1 \cdot 10$ & 0.97 \\
\hline $\mathbf{A}$ & 0.0 & 0.0 & 0.14 & 0.17 \\
\hline
\end{tabular}

* Extinctions of cultures measured at $680 \mathrm{~m} \mu$ in EEL colorimeter with 6 in. $\times \frac{5}{8}$ in. bacteriological test tube as optical cell and uninoculated medium as blank. Values shown are the averages of triplicate cultures.

\section{Composition of solidified media}

Different concentrations of Neopeptone between I and $4 \%(\mathrm{w} / \mathrm{v})$ were without obvious effect on growth. It could be replaced by $I \%(w / v)$ acid hydrolysate of casein (CA medium), or a mixture of amino acids (Aa medium) (Pl. 3, fig. I I, I3, I5) or by crude papain digest of horse muscle (PD medium). Omission of horse blood decreased, to some extent, the number of colonies which developed on plates, but since residual growth was still luxuriant blood was stimulatory rather than essential. In the presence of cysteine and absence or presence of blood, ascorbic acid or DTT could be omitted, separately, without adverse effect on growth. However, the omission of both compounds when cysteine was present, or of cysteine when ascorbic acid and/or DTT was present resulted in development of markedly fewer colonies than on control plates. These colonies had a thin, flat, dry appearance and the fact that they had developed at all was probably due to the presence of traces of essential compounds, possibly thiols, carried over in the inoculum at the time of streaking. Omission of all three compounds resulted in complete absence of growth. Thioglycollate at $100 \mu \mathrm{g} . / \mathrm{ml}$. replaced DTT in this medium but did not do so in CA or Aa media (Pl. 3, fig. 12, I4, I6) 


\section{The effect on growth of initial $\mathrm{pH}$ value}

Growth on solidified NP medium (blood omitted) was equally good at all $\mathrm{pH}$ values in the range 6.70 to 8.00 . In liquid medium (blood omitted) growth was tested in the range $\mathrm{pH} 7.60$ to 8.50 and was heavy at all these values. At $\mathrm{pH} 8.50$, however, the lag period was increased; growth was poor at $24 \mathrm{hr}$ but heavy at $48 \mathrm{hr}$.

\section{The effect on growth of drying the surface of the solidified medium}

Ten plates of NP medium were poured and allowed to set at room temperature (about $20^{\circ}$ ). Five of these were then placed in the incubator at $37^{\circ}$ and left to dry in an inverted, sloping position, with lids removed, for $15 \mathrm{~min}$. The remaining five plates were left at room temperature with lids on during this time and were subsequently called wet plates. Each plate of the dry and wet series was then streaked with one loopful of a culture of Clostridium novyi $\mathrm{CN} 755$ grown at $37^{\circ}$ in $\mathrm{RMB}$ for $\mathrm{I} 8 \mathrm{hr}$. The appearance of the colonies which developed after subsequent incubation for $24 \mathrm{hr}$ is shown in P1. I, fig. 4, 5. It was clear that whilst the condition of the surface of the medium with respect to 'free' moisture was not a determinant factor for growth it did have a marked effect upon the morphology of the colonies. Free moisture seemed to favour motility with formation of characterless spreading confluent growth.

\section{Preparation of solidified NP medium}

The solidified medium (NP medium) finally adopted for the routine plating of cultures of $C$. novyi type B had the composition shown in Table 2. The initial pH of the final medium was between $7 \cdot 6$ and $7 \cdot 8$. Since the presence of blood was not strictly essential for growth it was omitted when its presence would be likely to hinder observation of phenomena other than growth, e.g. formation of toxin antitoxin haloes, or modify certain pre-set conditions, e.g. initial $\mathrm{pH}$ value. In the following account the omission of blood is indicated where necessary.

Table 2. The composition of NP medium used for plating cultures of Clostridium novyi type $B$ CN 775

\begin{tabular}{|c|c|c|c|}
\hline & g. & & mg. \\
\hline Neopeptone* & Io & Cysteine hydrochloride & 100 \\
\hline Yeast extract* & 5 & Glutamine & 50 \\
\hline Liver extract $\dagger$ & 5 & Dithiothreitol & 100 \\
\hline Glucose & I0 & Horse blood & $\mathrm{I} 00 \mathrm{ml}$. \\
\hline Agar (Noble)* & 20 & Salts solution $\dot{\mp}$ & $5 \mathrm{ml}$. \\
\hline
\end{tabular}

Basal medium. To make $1000 \mathrm{ml}$. of medium the requisite quantities of Neopeptone, yeast extract, liver extract and glucose were dissolved in about $400 \mathrm{ml}$. glassdistilled water, the salts solution was added, the volume made to $500 \mathrm{ml}$. and the solution adjusted to $\mathrm{pH} 7 \cdot 6$ to $7 \cdot 8$. Agar dissolved in $500 \mathrm{ml}$. distilled water by autoclaving ( $12 \mathrm{I}^{\circ}$ for $5 \mathrm{~min}$.) was then added whilst the solution was still hot. Volumes of $18 \mathrm{ml}$. were quickly dispensed into $\mathrm{I} \mathrm{oz}$. screw-capped bottles and sterilized by auto- 
claving. When the medium was not used immediately it was stored at $4^{\circ}$ and melted when required.

Final plating medium. Liquefied portions of basal medium were allowed to cool to 37 to $40^{\circ}$. Horse blood $(2 \mathrm{ml}$.) was then added followed by $0.15 \mathrm{ml}$. of a solution ( $\mathrm{pH} 7 \cdot 6$ to $7 \cdot 8$ ) containing $(\mathrm{mg} . / \mathrm{ml}$.): cysteine hydrochloride, 12 ; glutamine, 6 ; DTT, 12. This solution was made just before use and sterilized by filtration through a Millipore GS membrane. Plates were then poured immediately, allowed to set (about $15 \mathrm{~min}$.) and dried at $37^{\circ}$ for not longer than $15 \mathrm{~min}$. Immediately after this the plates were streaked and quickly placed in anaerobic jars which were filled with the $\mathrm{H}_{2}+\mathrm{CO}_{2}$ mixture. Prepared and used in this way NP medium repeatedly supported rapid ( $18 \mathrm{hr}$ ) growth from the organisms in cultures of C. novyi type B grown for $24 \mathrm{hr}$ and $48 \mathrm{hr}$ in RMB. Even after storage of these RMB cultures for 2 or 3 weeks at room temperature many viable organisms were still present. Cultures grown in Brewer's medium for 24 and $48 \mathrm{hr}$ contained many viable organisms but after $72 \mathrm{hr}$ their numbers appeared to be greatly decreased (Pl. I, fig. I to 3 ).

$C A$ medium. This was essentially the same as NP medium but vitamin-free Casamino acids ( $1 \%, w / v)$ replaced the Neopeptone; liquid and solidified versions were found to be reliable. Growth could be obtained without horse blood but its presence was beneficial (Table 3). Cysteine with either ascorbic acid or DTT were essential for good rapid growth in liquid and solidified CA media; glutamine could be omitted without adverse effect and glucose could be decreased to as low as $0.12 \%(\mathrm{w} / \mathrm{v})$. Above $1 \%(w / v)$ glucose appeared to be unfavourable for growth (Table 3 ).

Table 3. The effect of varying some components of solidified NP and CA media on the colonial growth of Clostridium novyi type $B$ CN 755

\begin{tabular}{|c|c|c|}
\hline Basal media ( $\mathrm{pH} 7 \cdot 60)$ & Variation & $\begin{array}{l}\text { Growth* } \\
\text { No. colonies } \\
\text { developed } \\
\text { at } 18 \mathrm{hr}\end{array}$ \\
\hline $\begin{array}{l}\text { NP (blood } 10 \%, v / v ; \\
\text { glucose, I } \%, w / v)\end{array}$ & $\begin{array}{l}\text { Nil } \\
\text { YE } \dagger \\
\text { LE } \ddagger \text { omitted } \\
\text { YE }+ \text { LE omitted } \\
\text { Glucose at } 3 \% \\
\text { Salts\$ }\end{array}$ & $\begin{array}{r}80 \\
80 \\
80 \\
30 \\
20 \\
200\end{array}$ \\
\hline $\begin{array}{l}\text { CA (no blood; glucose, } \\
0.12 \%, w / v)\end{array}$ & $\begin{array}{l}\text { Nil } \\
\text { Glucose I } \% \\
\text { Glucose } 3 \% \\
\text { Glucose I } \%+\text { saltsई } \\
\text { Glucose } 1 \%+\text { blood }(10 \%, v / v)\end{array}$ & $\begin{array}{r}100 \\
40 \\
0 \\
30 \\
500\end{array}$ \\
\hline
\end{tabular}

\section{Miscellaneous solidified media}

Following the demonstration of the essential nature of the mixture of cysteine with DTT or ascorbic acid in NP and CA plating media, the suitability for growth of each of four other solidified media was tested. These were: RMB without meat particles 
(pH 7.20); RMB without meat particles and supplemented with blood (I0 \%, v/v); papain digest of horse muscle supplemented with sodium sulphate extract of horse muscle (HME, $10 \%, \mathrm{v} / \mathrm{v}, \mathrm{pH} 7.80$ ); Brewers medium without thioglycollate. Each of these media was supplemented, as described for NP medium, with cysteine, glutamine and DTT and solidified with agar $(2 \%, \mathrm{w} / \mathrm{v})$. Replicate plates of each medium were streaked with $0.03 \mathrm{ml}$. of a culture of Clostridium novyi CN 755 grown in RMB for $24 \mathrm{hr}$ and the plates then incubated at $37^{\circ}$ for $60 \mathrm{hr}$. The colonies and constituent bacilli are shown in Pl. 2, fig. 6 to IO. Smear preparations stained with fluorescent antiserum (Batty \& Walker, 1965) confirmed that the rods were those of C. novyi. Examination of the whole plates showed that whilst growth was most luxuriant on NP medium it was also good on the other media. No growth occurred on any of these media when the mixture of cysteine and DTT was omitted.

\section{Demonstration of toxinogenic colonies}

Clostridium novyi type B antitoxin was incorporated in media at one $\alpha$-unit $/ \mathrm{ml}$. The formation of toxin antitoxin haloes by individual colonies of C. novyi CN 755 is shown in Pl. 3, fig. I8. Although the morphology of the four colonies shown in Pl. 3, fig. I7, is identical, comparison of the densities of their toxin antitoxin haloes (Pl. 3, fig. 18) suggests that their toxinogenic capacities were different.

\section{DISCUSSION}

The essential need of Clostridium novyi type B for the mixture of cysteine with dithiothreitol (DTT) in addition to its need for strict anaerobiosis and for amino acids, components of the vitamin B complex and other unidentified factors (probably peptides) reveals its particularly fastidious character.

In neutral or slightly alkaline solution the oxidation of cysteine proceeds rapidly (Elliott, 1930; Crawhall \& Segal, I966; Leyden \& Morgan, 1967) so that under the conditions prevailing during pouring, setting and drying of plating media its loss is likely to be considerable and the final media useless for the cultivation of this organism. It is clear, however, from the work of Cleland (1964) that in admixture with DTT cysteine is protected. Use of cysteine +DTT in the present investigations has resulted in the transformation of apparently useless plating media into media which, being intrinsically complete, are capable of supporting luxuriant growth of Clostridium novyi type B. The results suggest that use of cysteine+DTT may provide the key to successful surface cultivation of other fastidious clostridia, and that the mixture might, therefore, be used with advantage in media employed for primary isolation of these bacteria. In plating media thioglycollate is unlikely to be of use for protection of cysteine since both of these compounds are oxidised by air at the same rate (Elliott, I930). The superior protection of thiols afforded by DTT results from its greater stability to oxidation by air and also from the non-reversible cyclization of an intermediate product, formed by its reaction with disulphides, which ensures the regeneration of thiol (Cleland, 1963).

Neither ascorbic acid nor DTT replace cysteine in solidified medium hence it appears that cysteine is required per se and not only as a reducing agent. SzentGyörgi, Együd \& McLaughlin (1967) reported that inhibition of bacterial growth by certain keto-aldehydes $\left(\mathrm{C}_{4}-\mathrm{C}_{6}\right.$ homologues of methylglyoxal) was instantaneously annulled by adding cysteine because of its ready reaction with these aldehydes. If such 
an annullment of inhibition is a determining factor for the growth of $C$. novyi type B in the media used in the present work, the necessity for maintaining cysteine in the thiol form becomes clear.

The unsurpassed success of Robertson meat broth (Willis, 1965) for primary isolation and subsequent maintenance of clostridia probably reflects an adequate content of thiol and all other essential compounds.

The patience, willing co-operation and expertise of both Messrs A. E. Jones and E. J. Kentish who took the photographs is gratefully acknowledged. My thanks are also due to Misses B. Hill and F. Smith for able technical assistance.

\section{REFERENCES}

Batty, I., Buntain, D. \& WalkeR, P. D. (1964). Clostridium oedematiens; A cause of sudden death in sheep, cattle and pigs. Vet. Rec. 76, II 5 .

BATTY, I. \& WALKER, P. D. (1965). Colonial morphology and fluorescent labelled antibody staining in the identification of species of the genus Clostridium. J. appl. Bact. 28, I22.

Cleland, W. W. (1964). Dithiothreitol. A new protective reagent for SH groups. Biochemistry 3, 480.

Crawhall, J. C. \& Segal, S. (1966). Dithiothreitol in the study of cysteine transport. Biochim. biophys. Acta $121,215$.

Cruickshank, R. (1965). Clostridium. I: The gas-gangrene group. In Medical Microbiology. A Guide to the Laboratory Diagnosis and Control of Infection, I Ith ed. p. 320. Edinburgh and London: E. \& S. Livingstone Ltd.

Elliotr, K. A. C. (1930). XXXVII. On the catalysis of the oxidation of cysteine and thioglycollic acid by iron and copper. Biochem. J. 24, 310.

Khairat, O. (1966). Efficient general-purpose culture medium for aerobes \& anaerobes. Can. J. Microbiol. 12, 323.

LEYDEN, D. E. \& MORGAN, W. R. (1967). Stabilisation of solutions of cysteine and its derivatives. Can. J. Biochem. 45, 6II.

Moore, W. E. C. (1966). Techniques for routine culture of fastidious anaerobes. Int. J. Syst. Bact. $16(2), 173$.

Szent-Györgi, A., Együd, L. G. \& McLaughlin, J. A. (1967). Keto aldehydes and cell division. Science, N.Y. 155, 539.

TaKarabe, M. (1960). Studies on the nutritional requirements of some strains of Clostridium novyi. Jap. H. Bact. 15 (8), 785.

WILlis, A. T. (1965). Media for clostridia. Lab. Practice 14 (6), 690.

\section{EXPLANATION OF PLATES}

\section{Plate I}

Growth of Clodstridium novyi type B CN 755 (culture 79/12) on solidified NP medium ( $\mathrm{pH} 7 \cdot 80$ ); blood present. Whole plates $\times 0.8$. Bacilli from each type of colony were shown to be $C$. novyi by the fluorescent antibody technique.

Fig. I. Plate streaked with a culture grown for $24 \mathrm{hr}$ in Brewer medium.

Fig. I $a$. As fig. I, but enlarged to show variable morphology of colonies. $\times 2$.

Fig. 2. As fig. I, but the same culture at $48 \mathrm{hr}$.

Fig. $2 a$. As fig. 2, but enlarged to show variable morphology of colonies. $\times 2$.

Fig. 3. As fig. I, but the same culture at $72 \mathrm{hr}$. There is almost complete absence of viable cells.

The effect of drying the surface of NP medium on the morphology of colonies of C. novyi type B CN 755 .

Fig. 4. C. novyi CN 755 (culture 68/13) grown at $37^{\circ}$ for $24 \mathrm{hr}$ in Robertson meat broth, streaked on a wet plate of NP medium ( $\mathrm{pH} 7.80$ ) and incubated in $\mathrm{H}_{2}+\mathrm{CO}_{2}$ for $24 \mathrm{hr}$ at $37^{\circ} . \times 6.5$.

Fig. 5. As fig. 4, but the same culture streaked on to a dried plate of NP medium. $\times 6.5$. 

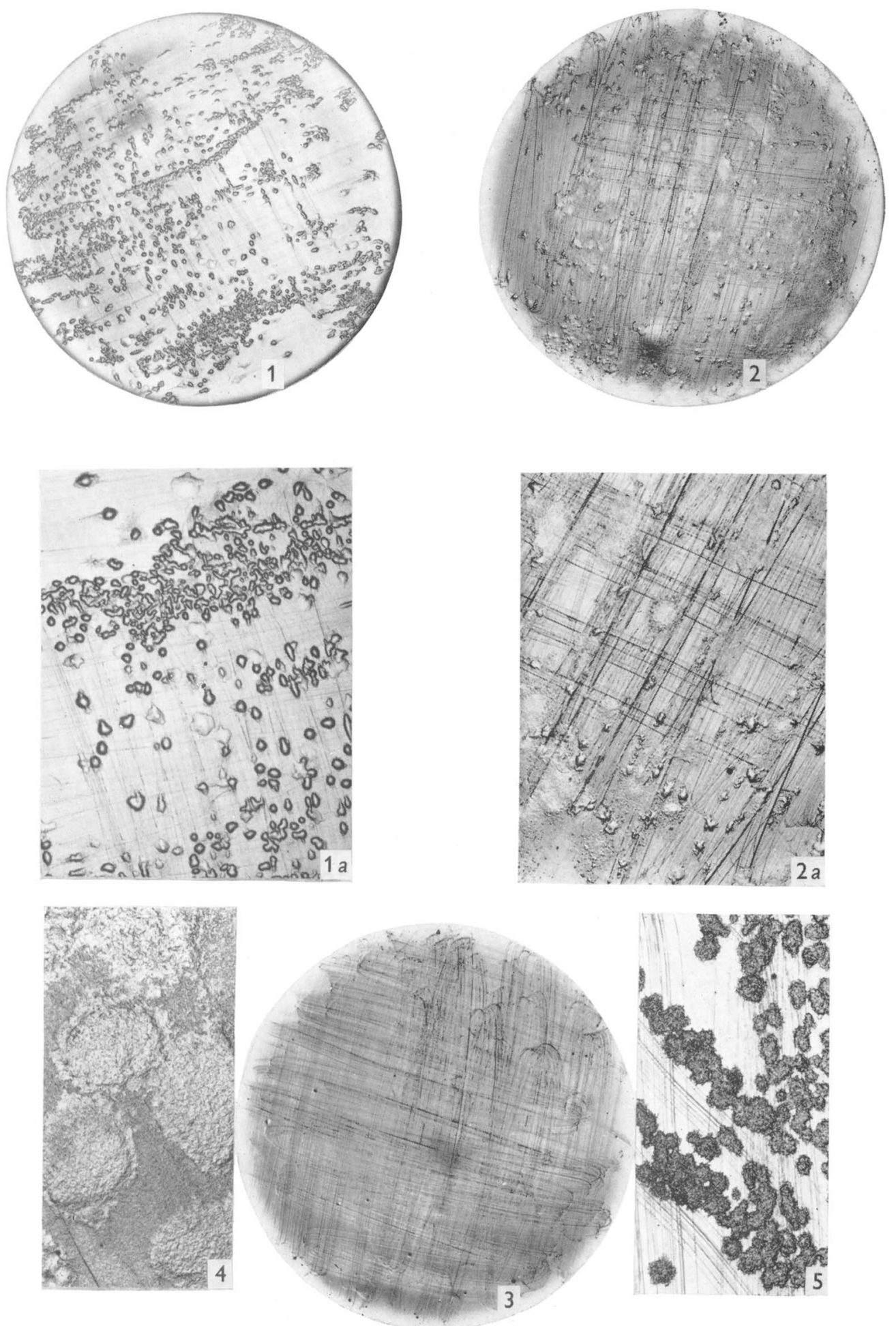

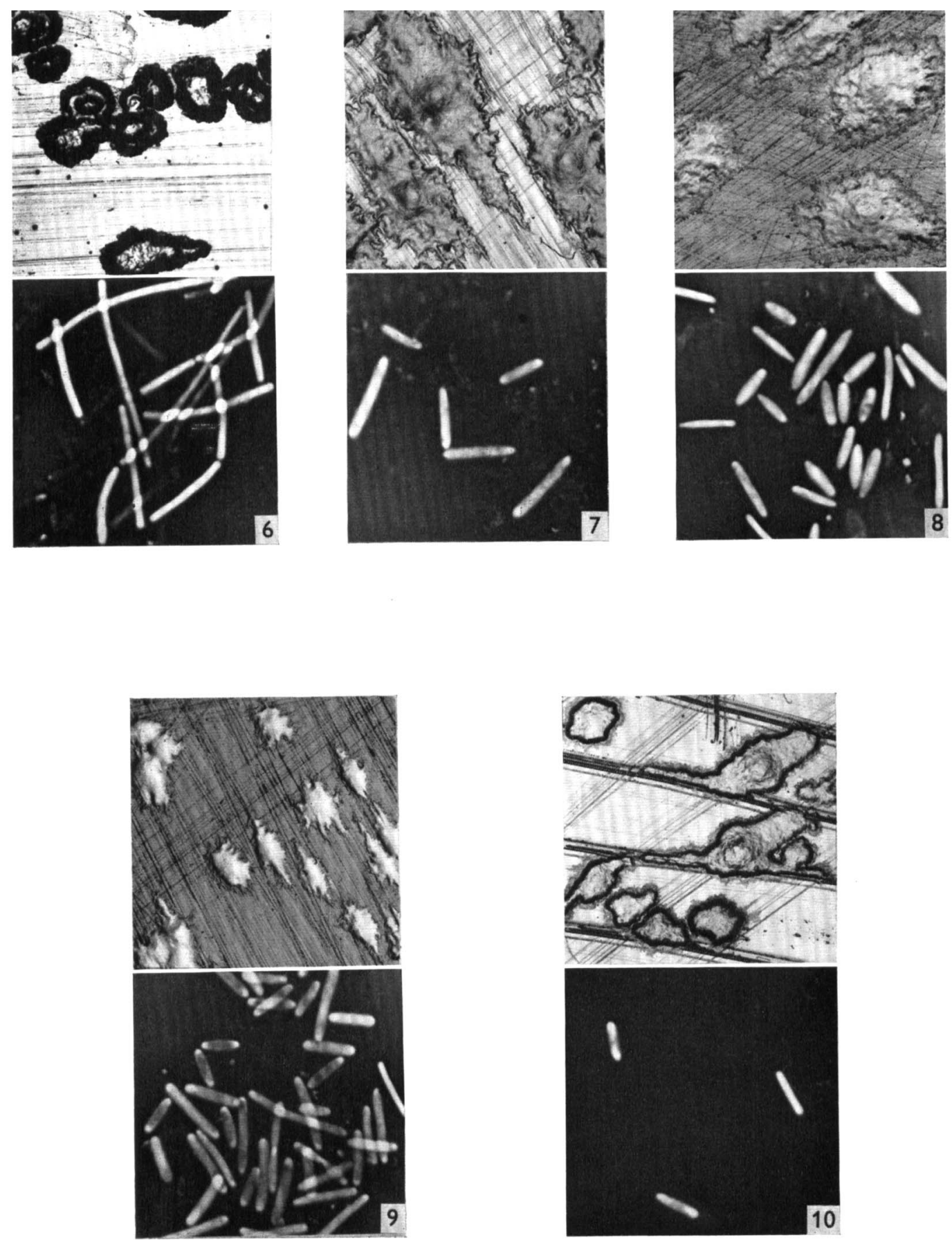

W. B. MOORE 

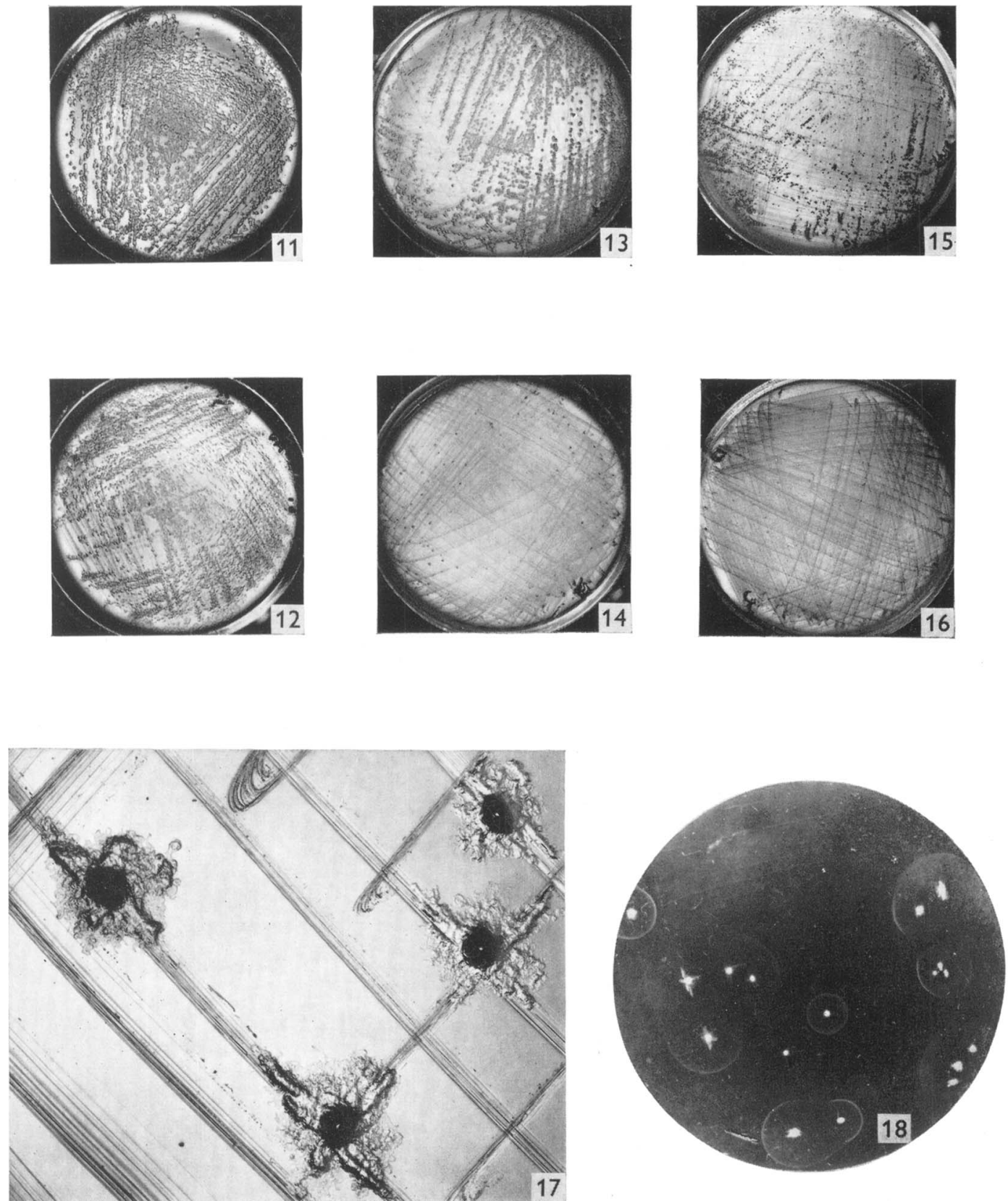

W. B. MOORE 



\section{Plate 2}

Colonial and cellular morphology of $C$. novyi type B CN 755 (culture 83/2) on each of five media supplemented just before use with cysteine, glutamine and dithiothreitol (DTT) $(\mu \mathrm{g} . / \mathrm{ml}$. $)=100+$ $50+100$, respectively. An inoculum was grown from a single colony in Robertson meat broth for $24 \mathrm{hr}$ at $37^{\circ}, 0.03 \mathrm{ml}$. spread over replicate plates of each medium which were then incubated in $\mathrm{H}_{2}+\mathrm{CO}_{2}$ for $60 \mathrm{hr}$ at $37^{\circ}$. Bacilli, $\times \mathrm{I} 630$; colonies, $\times 5.5$. Bacilli of colonies shown to be $C$. novyi by the fluorescent antibody technique.

Fig. 6. NP medium, blood present ( $\mathrm{pH} 7 \cdot 80)$.

Fig. 7. Papain digest of horse muscle containing sodium sulphate extract of horse muscle (10\%, $\mathrm{v} / \mathrm{v} ; \mathrm{pH} 7 \cdot 80$ ).

Fig. 8. Robertson meat broth without meat particles $(\mathrm{pH} 7 \cdot 20)$.

Fig. 9. As fig. 8 but supplemented with horse blood (10 \%,v/v).

Fig. 10. Brewer medium without thioglycollate, agar at $2 \%(w / v)$.

Plate 3

Replacement of dithiothreitol (DTT) by thioglycollate. One drop $(0.03 \mathrm{ml}$.) of $24 \mathrm{hr}$ culture of C. novyi CN 755 (culture 83/2) grown in Robertson meat broth, spread over the surface of each plate and incubated for $48 \mathrm{hr}$ at $37^{\circ}$. All media supplemented with cysteine (100 $\mu \mathrm{g} . / \mathrm{ml}$.) and glutamine (50 $\mu \mathrm{g} . / \mathrm{ml}$.); all at $\mathrm{pH} 7 \cdot 6-7 \cdot 8$.

Fig. I I. NP medium (blood present) +DTT (I00 $\mu \mathrm{g} . / \mathrm{ml}$.).

Fig. I2. NP medium (blood present) + thioglycollate (100 $\mu \mathrm{g} . / \mathrm{ml}$.).

Fig. 13. CA medium (no blood)+DTT.

Fig. 14. CA medium (no blood) + thioglycollate.

Fig. I5. Aa medium (no blood)+DTT.

Fig. I6. Aa medium (no blood) + thioglycollate.

Fig. 17. Morphology of colonies of C. novyi CN 755 (culture 6I/I6) after growth for $48 \mathrm{hr}$ on Aa medium (no blood) containing cysteine ( $100 \mu \mathrm{g} . / \mathrm{ml}$.), glutamine $(50 \mu \mathrm{g} . / \mathrm{ml}$.), DTT (100 $\mu \mathrm{g} . / \mathrm{ml}$.) and $C$. novyi type $\mathrm{B}$ antitoxin (one $\alpha$-unit $/ \mathrm{ml}$.). Magnification $\times 5$.

Fig. 18. Whole plants bearing the 4 colonies shown in fig. 17 , after storage at $4^{\circ}$ for 4 days. Different toxin-producing capacities are suggested by the different densities of the toxin antitoxin haloes. $\times 0.8$. 